\title{
Vulvar Squamous Cell Papillomatosis
}

National Cancer Institute

\section{Source}

National Cancer Institute. Vulvar Squamous Cell Papillomatosis. NCI Thesaurus. Code C40290.

A benign neoplastic process characterized by the presence of multiple vestibular papillomas in the vulva. 